\title{
Quantitative Comparison of Permanent Magnet Linear Machines for Ropeless Elevator
}

\author{
Hua Fan ${ }^{1}$, K. T. Chau ${ }^{1}$, Chunhua Liu ${ }^{2}$, Zhen Zhang ${ }^{1}$ and Chun Qiu ${ }^{1}$ \\ 1 Department of Electrical and Electronic Engineering, The University of Hong Kong, Hong Kong, China \\ Shenzhen Institute of Research and Innovation, The University of Hong Kong, Hong Kong, China \\ 2 School of Energy and Environment, City University of Hong Kong, Hong Kong, China
}

\begin{abstract}
This paper presents three configurations of doublesided long-stator type permanent magnet linear machines (PMLMs) as possible candidates for the ropeless elevator propulsion system. First, the design criteria and considerations are discussed in detail. Then the proposed PMLM configurations are calculated and compared by using finite element method (FEM). By comparing three different configurations of the PMLM, the characteristics of the translator mass, propulsion forces, detent forces, and no-load EMFs are contrasted and analyzed. Finally, quantitative comparison results are concluded, which verifies the validity of the machine designs and potential application for the lift.
\end{abstract}

Keywords-finite element method; linear machines; quantitative comparison; ropeless elevator

\section{INTRODUCTION}

Ropeless elevators have attracted more and more attention in recent years. There are two main drawbacks of the conventional elevators with steel cable, especially when they are used in mid-rise and high-rise buildings. One is that in 250 -m-high buildings, the conventional elevators occupy $30 \%$ of the total floor space [1-3]. Another problem is that as the height of buildings increases, the cable mass and vertical vibration will increase as well, resulting in the difficulty of controlling the elevator in the skyscrapers. As the key part of ropeless elevator system, linear machine is very suitable for transportation due to its little limitation on building height and space requirement [4-5].

The linear switched reluctance machines (LSRMs) are presented and compared in [6-9], which offer the advantages of low cost and simple construction. However, due to the disadvantages of low torque density and large force ripple, permanent magnet linear machines become more and more attractive [10-12]. The permanent magnet linear synchronous motors (PMLSMs) have been proposed in [13]. It only focuses on the optimal structure design for minimizing the detent force of PMLSM. Furthermore, due to the harder installation and higher cost, the transverse flux LSRMs are not adopted in this study [14-17].

The purpose of this paper is to present three configurations of double-sided long-stator type permanent magnet linear machines (PMLMs) as possible candidates for the ropeless elevator propulsion system. The double-sided stator is adopted to reduce the detent force between the translator and stator of the PMLM, so that the motor can be more compact. In order to reduce the weight of mover, the long-stator type is chose. This paper is organized as follows. All three PMLM topologies proposed in this paper are presented, and the design criteria and dimension parameters are detailed in Section II. The designed PMLMs are calculated and compared by using finite element method (FEM) in Section III. The no-load EMFs, translator mass, propulsion forces, and detent forces are contrasted. Section IV has comparison results of all three machine configurations and the conclusions drawn from the research are presented.

\section{MACHINE TOPOLOGIES}

Fig. 1 shows the schematic diagram of the ropeless elevator system. From the front view on the left, it can be seen that the long stator is fixed in the elevator shaft while the translator is fastened to the elevator vehicle. It is the moving part of PMLM, which can move with the vehicle. Furthermore, from the top view on the right, it can be seen that there are two sets of PMLMs on both sides of the elevator to increase the propulsion force.

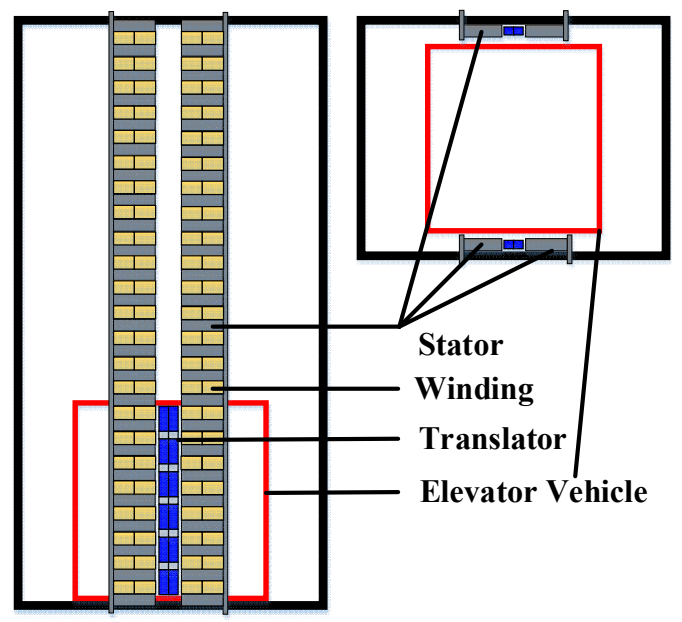

Fig. 1. Ropeless Elevator system

All three machine topologies are shown in Fig. 2, and each configuration is designed to fit in the 1.96-m-tall elevator. In order to compare the machine performances, the stator dimensions of all three PMLMs are designed to be the same. The stator is composed of two groups of iron cores which are placed on two sides. These iron cores are fixed to the hoist way, which are faced to each other with concentrated windings. And a 12-slot/10-pole structure is adopted to reduce the detent force and suppress the back EMF harmonics. Furthermore, the translator structures can be divided into three different cases. Fig. 2(a) shows the topology of mounted 
permanent magnet (PM) configuration. As can be seen, the translator consists of the mover iron yoke and permanent magnets mounted on its both sides. Fig. 2(b) shows the topology of inserted PM configuration. Instead of mounted on the back iron of the translator, the permanent magnets are placed between the mover iron yokes, which are magnetized in the normal orientation. Fig. 2(c) shows the topology of Halbach array PM configuration, which has no back iron in the translator. It is a compact configuration with no yoke in the design.

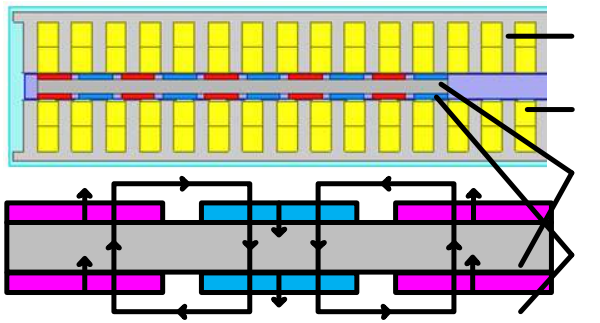

Stator back-iron

(a)

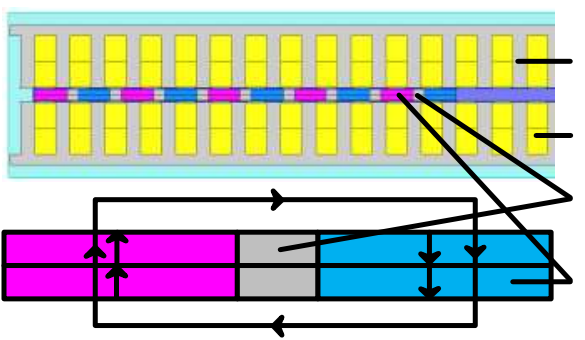

Stator back-iron

Coil

(b)

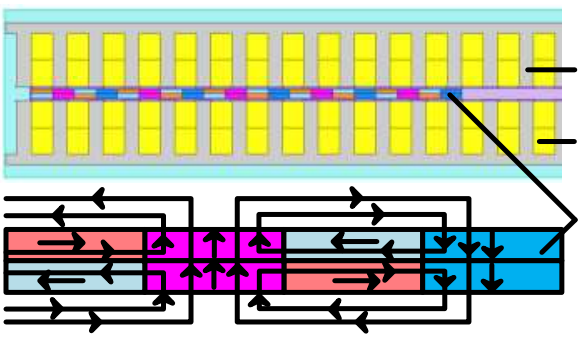

Stator back-iron

Coil

Magnet

(c)

Fig. 2. Three PMLM topologies. (a) Mounted PM type. (b) Inserted PM type. (c) Halbach array PM type.

In order to compare the machine performances for the three PMLM topologies, there are some design criteria to be applied to all three PMLMs. First, the stator dimensions of the machine configurations are held constant, and so are the total lengths of machine translators. Second, three topologies are designed with the same winding excitation current 12 A using the control variate method to compare their propulsion forces [18-19]. Third, though the lengths or heights of the permanent magnets are different, the volumes of total permanent magnets are kept the same in the three PMLMs. Furthermore, the 12slot/10-pole structure is adopted in each machine configuration. Finally, there are two PMLMs in the designed ropeless elevator so that the output force is twice the propulsion force value of the designed PMLM.
As discussed in the design criteria, the stator length is designed to be $1960 \mathrm{~mm}$ with 48 slots, and the translator length is designed as $480 \mathrm{~mm}$ with 10 poles in each of the three machine configurations. And the velocities of all three translators are set as $5 \mathrm{~m} / \mathrm{s}$, aiming to enable the passengers to have access to the elevator vehicle within 30 seconds in the multi elevator system [20]. Furthermore, due to the height limitation of the elevator vehicle, the length of the needs to be lower than the vehicle height. The key design data of the three presented PMLMs are shown in Table I.

TABLE I

KEY DATA OF PROPOSED MACHINES

\begin{tabular}{llll}
\hline \hline Item & Case 1 & Case 2 & Case 3 \\
\hline Rated current & $12 \mathrm{~A}$ & $12 \mathrm{~A}$ & $12 \mathrm{~A}$ \\
Elevator velocity & $5 \mathrm{~m} / \mathrm{s}$ & $5 \mathrm{~m} / \mathrm{s}$ & $5 \mathrm{~m} / \mathrm{s}$ \\
Elevator length & $1960 \mathrm{~mm}$ & $1960 \mathrm{~mm}$ & $1960 \mathrm{~mm}$ \\
Air gap length & $1.5 \mathrm{~mm}$ & $1.5 \mathrm{~mm}$ & $1.5 \mathrm{~mm}$ \\
Translator length & $480 \mathrm{~mm}$ & $480 \mathrm{~mm}$ & $480 \mathrm{~mm}$ \\
Winding turns per phase & $164 \mathrm{turns}$ & $164 \mathrm{turns}$ & $164 \mathrm{turns}$ \\
Translator PM width & $39 \mathrm{~mm}$ & $36.89 \mathrm{~mm}$ & $24 \mathrm{~mm}$ \\
Translator PM height & $6 \mathrm{~mm}$ & $6.34 \mathrm{~mm}$ & $4.875 \mathrm{~mm}$ \\
Translator PM number & 20 & 20 & 40 \\
\hline \hline
\end{tabular}

\section{PERFORMANCE ANALYSIS}

By using the FEM, the machine performances of the proposed three PMLMs are calculated and compared. The propulsion forces, detent forces, no-load EMFs and translator mass of the PMLMs are analyzed and compared.

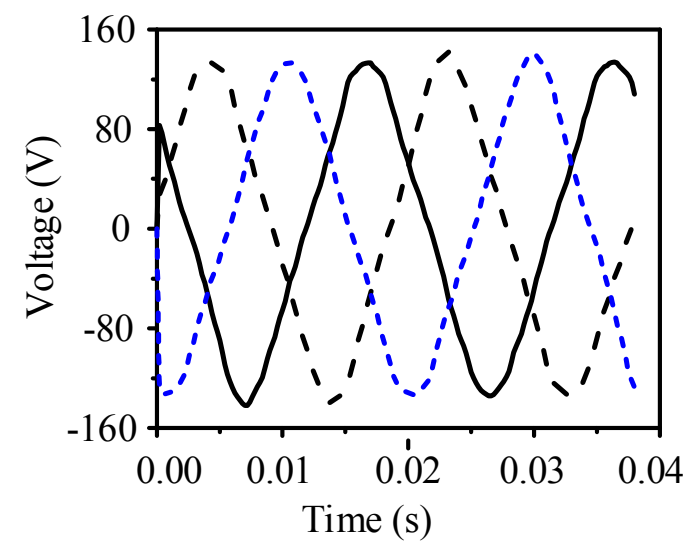

(a)

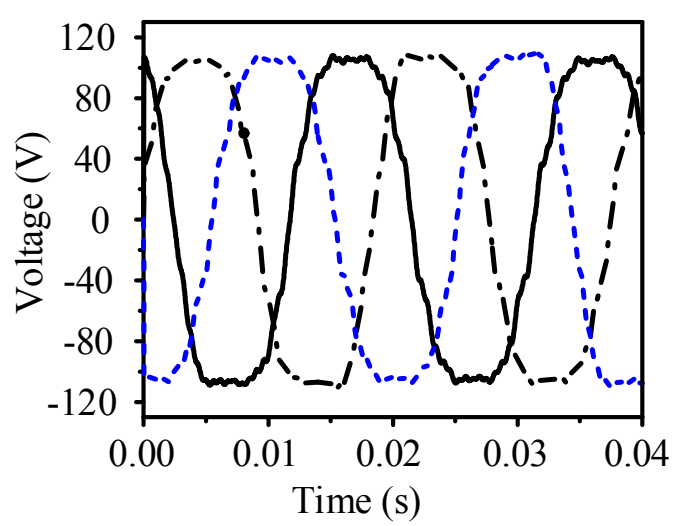

(b) 


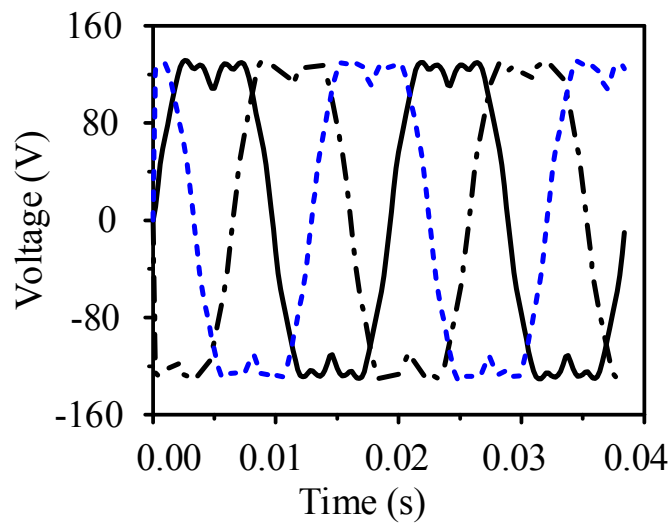

(c)

Fig. 3. EMF waveforms of three PMLMs. (a) Mounted PM type. (b) Inserted PM type. (c) Halbach array PM type.

First, the basic machine characteristics of the three PMLMs are shown in Fig. 3 and Fig. 4. Fig. 3 shows the amplitude of the no-load EMF in the mounted PM configuration is nearly the same as that in the Halbach array PM configuration, which is $133.82 \mathrm{~V}$ and $130.40 \mathrm{~V}$, respectively. From Fig. 3(c), it can be seen that the waveform of no-load EMF is more like trapezoidal than sinusoidal, which means that the Halbach array machine can be operated in the brushless DC (BLDC) mode [21-22]. In the Halbach array configuration, only 2 segments per pole are employed to save the cost of fabrication, resulting in the trapezoidal waveform. Because the excited current is sinusoidal during the comparison, the sinusoidal wave of case 1 is better than the trapezoidal wave of case 3 .

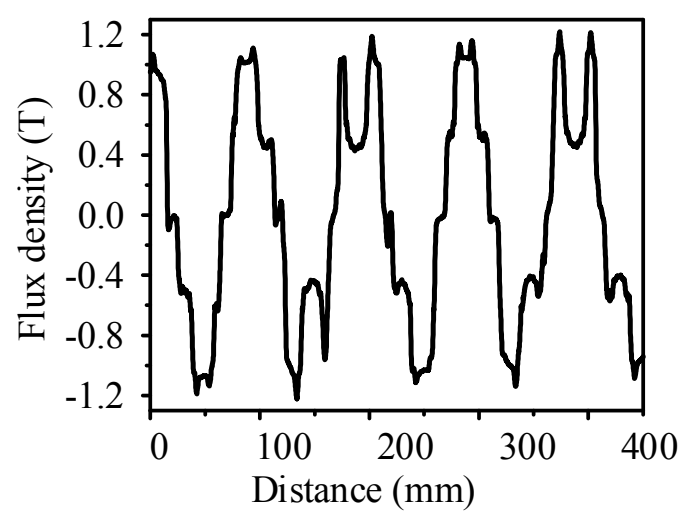

(a)

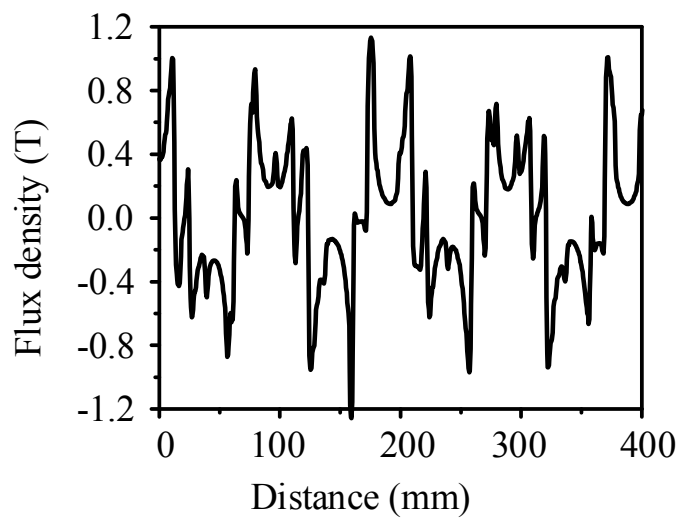

(b)

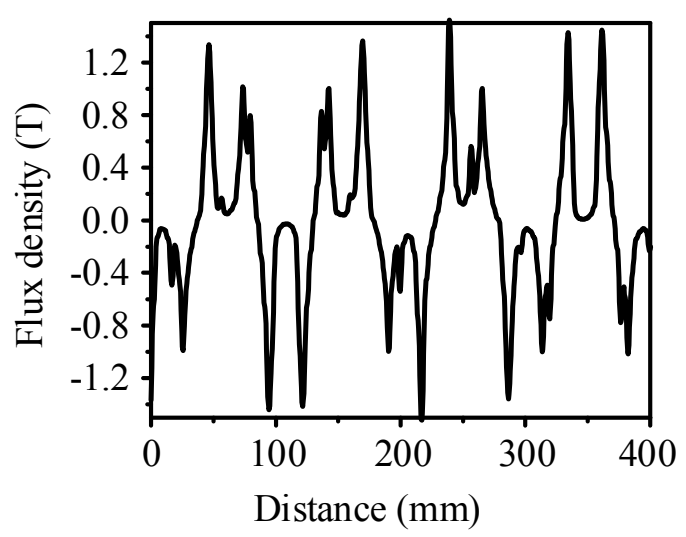

(c)

Fig. 4. Airgap flux density of three PMLMs. (a) Mounted PM type. (b) Inserted PM type. (c) Halbach array PM type.

In order to compare the machine performances of three PMLMs, the control variate method is adopted by keeping the winding excitation currents both the same rated value and the same sinusoidal waveform shape. In Fig. 4, the airgap flux density waveforms of all three machines are shown. And the machine performances are given in Fig. 5 and Fig. 6. Fig. 5 shows the propulsion forces of three different PMLMs. As can be seen in Fig. 5(c), the propulsion force of Halbach array PM configuration is larger than the other two configurations. Therefore, the Halbach array PM configuration is the preferable choice in terms of the machine propulsion force.

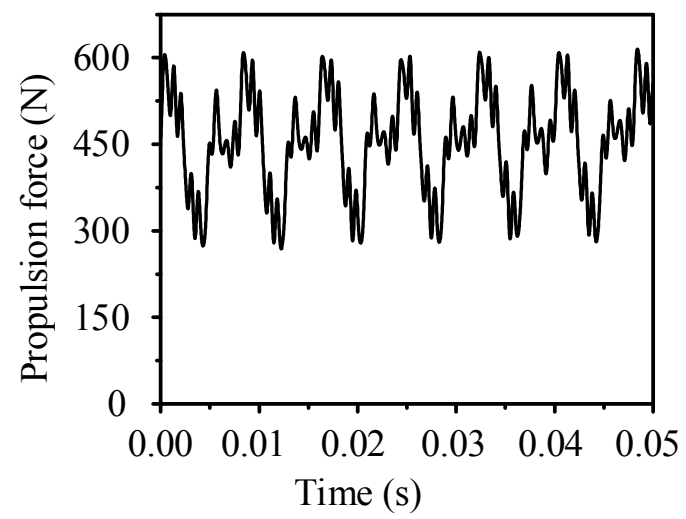

(a)

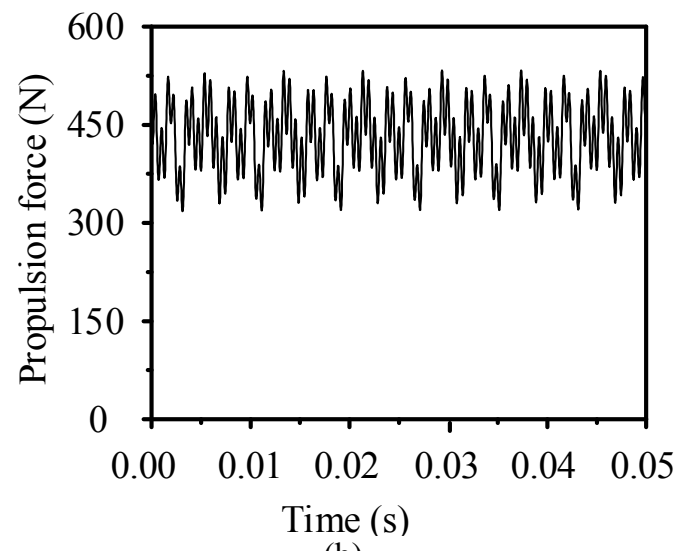

(b) 


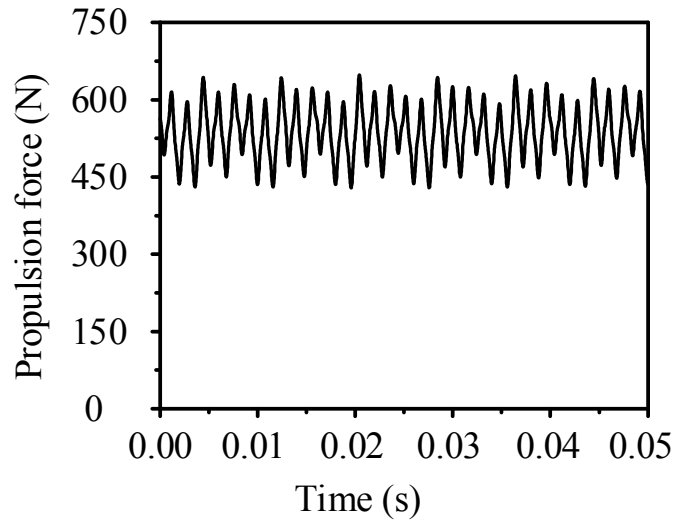

(c)

Fig. 5. Propulsion force of three PMLMs. (a) Mounted PM type. (b) Inserted PM type. (c) Halbach array PM type.

Furthermore, the detent forces of three configurations are calculated, and the results are illustrated in Fig. 6. As can be seen, the amplitude of the detent force is $24.83 \mathrm{~N}, 30.76 \mathrm{~N}$, and $23.65 \mathrm{~N}$, which is $5.46 \%, 7.13 \%$, and $4.41 \%$ the amplitude of the propulsion force $454.99 \mathrm{~N}, 431.16 \mathrm{~N}$ and $536.62 \mathrm{~N}$ in Fig. 6(a), Fig. 6(b), and Fig. 6(c), respectively. The ratio of the detent force to the propulsion force is the smallest in the case 3. As a result, the Halbach array PM configuration is proven to be desirable for the ropeless elevator system in terms of minimizing the detent force.

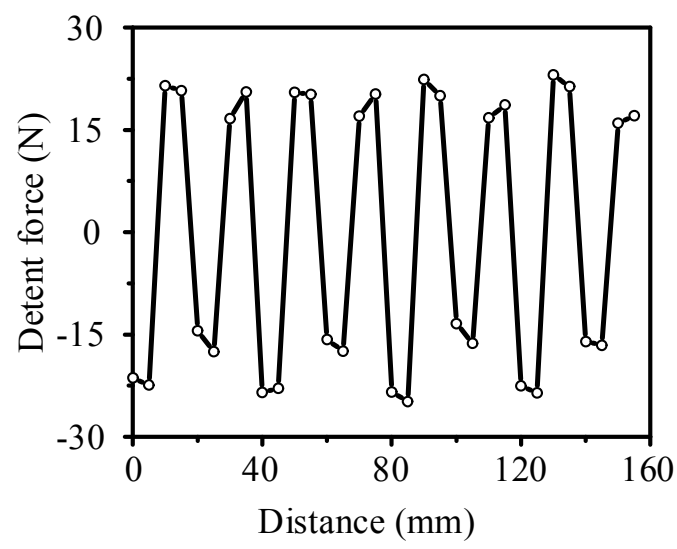

(a)

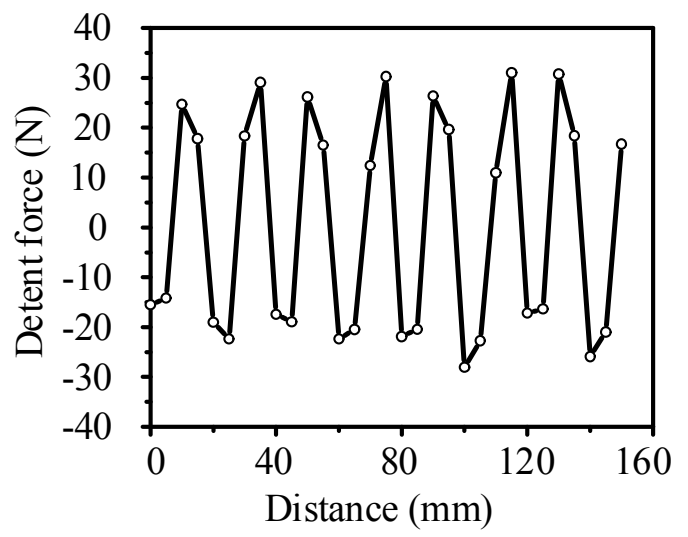

(b)

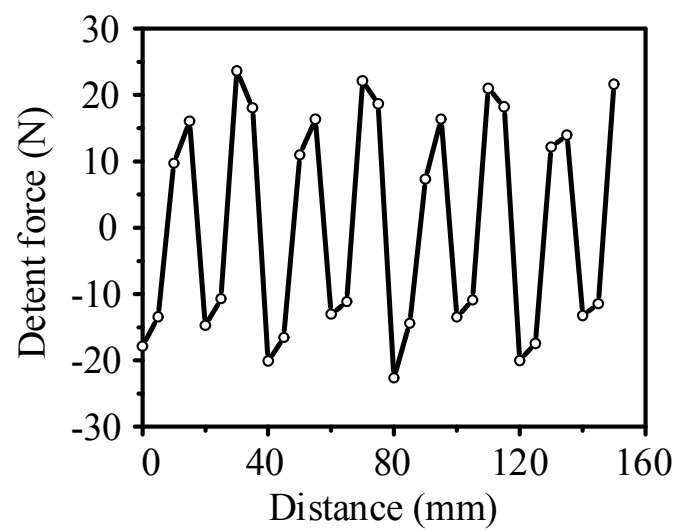

(c)

Fig. 6. The detent force of three PMLMs. (a) Mounted PM type. (b) Inserted PM type. (c) Halbach array PM type.

Finally, the payload capability is influenced by both the propulsion force, and the total mass of the machine. The propulsion force versus the translator position is shown in Fig.7. As the stator dimensions and the windings are all the same in the three different machine configurations, the mass of different PMLMs needs to be calculated and compared. Therefore, the mass of the translators are listed in Table II. Due to the ironless configuration of the Halbach array PMLM, the mass of case 3 is the lowest. In conclusion, the Halbach array configuration is the preferable choice in terms of weight.

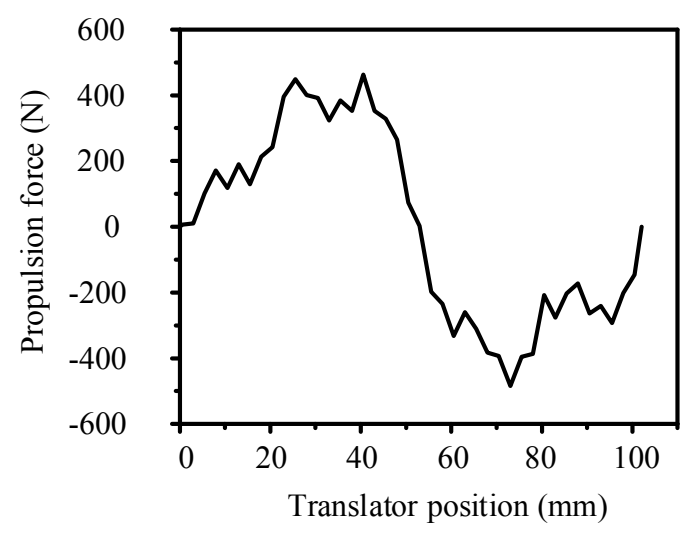

(a)

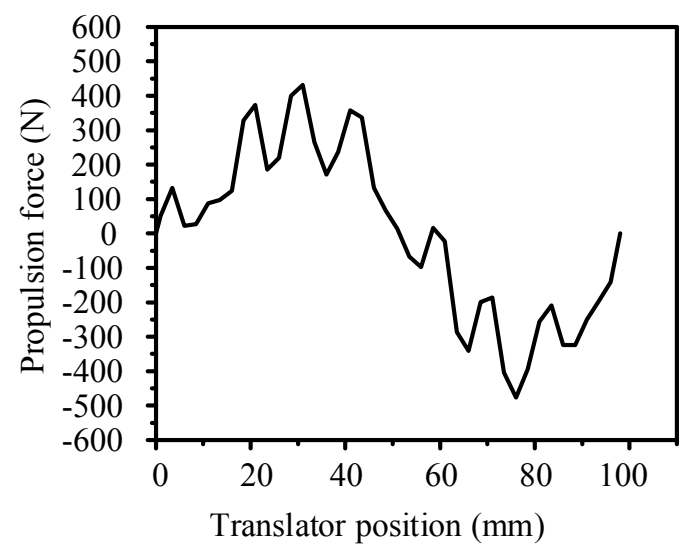

(b) 


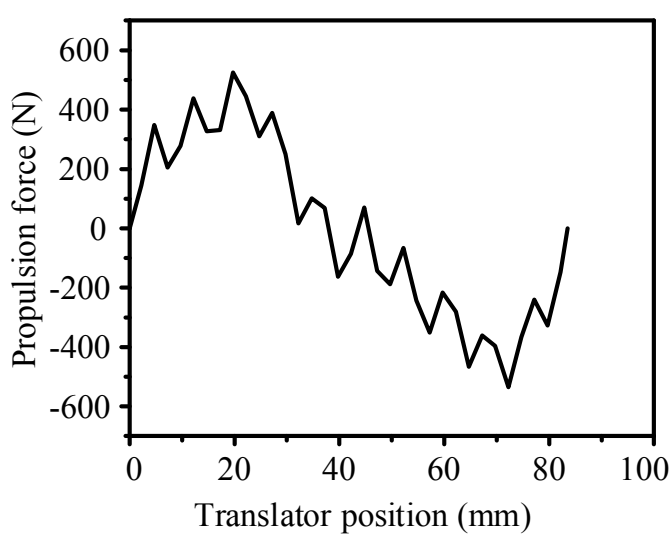

(c)

Fig. 7. The propulsion force versus the translator position.

(a) Mounted PM type. (b) Inserted PM type. (c) Halbach array PM type.

TABLE II

PERFORMANCES OF COMPARED MACHINES

\begin{tabular}{llllc}
\hline \hline Item & Case 1 & Case 2 & Case 3 & Best \\
\hline Propulsion force & $454.99 \mathrm{~N}$ & $431.16 \mathrm{~N}$ & $536.62 \mathrm{~N}$ & Case 3 \\
Force ripple & $35.20 \%$ & $23.73 \%$ & $20.75 \%$ & Case 3 \\
$\begin{array}{l}\text { Detent force } \\
\text { percentage }\end{array}$ & $5.46 \%$ & $7.13 \%$ & $4.41 \%$ & Case 3 \\
$\begin{array}{l}\text { Voltage amplitude } \\
\text { Translator mass }\end{array}$ & $133.82 \mathrm{~V}$ & $106.94 \mathrm{~V}$ & $131.40 \mathrm{~V}$ & Case 1 \\
\hline \hline
\end{tabular}

\section{CONCLUSION}

Three configurations of PMLMs are presented and analyzed, including the mounted PM configuration, normal inserted PM configuration, and Halbach array PM configuration. The performances are calculated and compared by the FEM. The comparison results of three PMLMs are summarized in Table II. It tells that the Halbach array PMLM configuration is the preferable choice in most categories. Specifically, the detent force percentage of the Halbach array topology is the smallest. Furthermore, the total mass of the Halbach array PMLM is the lowest. The validity of three machine designs is proved by the characteristics and performances. Therefore, it indicates that the proposed machines can be applied in the multi elevator technology, thus increasing the transport capacities and efficiency in the skyscrapers.

\section{ACKNOWLEDGMENT}

This work was supported by a grant (Project No. 201309176048) from the HKU Small Project Funding, Hong Kong Special Administrative Region, China. Also, it was supported by the grant of Basic Research Program (Project Code: JCYJ20120831142942515), Science, Technology and Innovation Commission of Shenzhen Municipality (SZSTI), China. Moreover, it was supported by the grant from School of Energy and Environment, CityU, HKSAR, China.

\section{REFERENCES}

[1] H. Lim and R. Krishnan, "Ropeless elevator with linear switched reluctance motor drive actuation systems", IEEE Trans. Ind. Electron., vol. 54, no. 4, pp.2209-2218, Aug. 2007.

[2] C. Liu, K. T. Chau, and X. D. Zhang, "An efficient wind-photovoltaic hybrid generation system using doubly excited permanent-magnet brushless machine", IEEE Trans. Ind. Electron., vol. 57, no. 3 pp.831839, Feb. 2010

[3] Z. G. Sun, N. C. Cheung, S. W. Zhao, and W. C. Gan, "Magnetic analysis of switched reluctance actuators in levitated linear transporters", IEEE Trans. Veh. Technol., vol. 59, no. 9, pp.4280-4288, Nov. 2010.

[4] T. Ishii, "Elevators for skyscrapers", IEEE Spectr., vol. 31, no. 9, pp.4246, Sept. 1994.

[5] K. T. Chau, C. C. Chan, and C. Liu, "Overview of permanent-magnet brushless drives for electric and hybrid electric vehicles." Industrial Electronics, IEEE Trans. Ind. Electron., vol 55, no. 6, pp.2246-2257, Jun. 2008.

[6] C. Liu, Z. Jin and K. T. Chau, "A novel flux-controllable vernier permanent-magnet machine." IEEE Trans. Magn., vol. 47, no. 10, pp.4238-4241, May. 2011.

[7] N. S. Lobo , H. S. Lim and R. Krishnan, "Comparison of linear switched reluctance machines for vertical propulsion application: Analysis, design, and experimental correlation", IEEE Trans. Ind. Appl., vol. 44, no. 4, pp.1134-1142, Jul. 2008.

[8] K. T. Chau and Y. S. Wong. "Overview of power management in hybrid electric vehicles", Energy Conv. and Management, vol. 43, no. 15, pp.1953-1968, 2002.

[9] C. Liu, K. T. Chau and W. Li, "Comparison of fault-tolerant operations for permanent-magnet hybrid brushless motor drive", IEEE Trans. Magn., vol. 46, no. 6, pp.1378-1381, Jun. 2010.

[10] K. Yoshida and H. Matsumoto. "Propulsion and guidance simulation of a high-temperature superconducting bulk ropeless linear elevator", IEEE Trans Magn., vol 40, no. 2, pp.615-618, Mar. 2004.

[11] C. Liu, K. T. Chau and Z. Zhang, "Novel design of double-stator singlerotor magnetic-geared machines", IEEE Trans. Magn., vol. 48, no. 11, pp.4180-4183, 2012.

[12] Y. W. Zhu, D. H. Koo and Y. H. Cho, "Detent force minimization of permanent magnet linear synchronous motor by means of two different methods", IEEE Trans. Magn., vol. 44, no. 11, pp.4345-4348, Nov. 2008.

[13] C. T. Liu, K. S. Su and J. W. Chen, "Operational stability enhancement analysis of a transverse flux linear switched-reluctance motor", IEEE Trans. Magn., vol. 36, pp.3699-3702, Aug. 2000.

[14] W. Li, K. T. Chau, C. Liu, and C. Qiu, "Design and Analysis of a FluxControllable Linear Variable Reluctance Machine", IEEE Trans.Appl. Supercon., vol. 24, no. 3, pp.1-4, Jun. 2014.

[15] C. Liu, K. T. Chau, W. Li and C. Yu, "Efficiency optimization of a permanent-magnet hybrid brushless machine using DC field current control", IEEE Trans. Magn., vol. 45, no. 10, pp.4652-4655, Oct. 2009.

[16] H. S. Lim , R. Krishnan and N. S. Lobo, "Design and control of a linear propulsion system for an elevator using linear switched reluctance motor drives", IEEE Trans. Ind. Electron., vol. 55, no. 2, pp.534-542, Feb. 2008.

[17] C. Liu , J. Zhong and K. T. Chau, "A novel flux-controllable vernier permanent-magnet machine", IEEE Trans. Magn., vol. 47, no. 10, pp.4238-4241, Oct. 2011.

[18] A. S. Abd-Rabou, H. M. Hasanien and S. M. Sakr, "Design development of permanent magnet excitation transverse flux linear motor with inner mover type", IET elec. power appli., vol 4, no.7, pp.559-568, 2010.

[19] Liu, Yong, Z. Q. Zhu, and David Howe, "Direct torque control of brushless DC drives with reduced torque ripple," Industry Applications, IEEE Trans. Ind. Appli., vol.41, no.2, pp.599-608, Mar. 2005.

[20] S. G. Lee, S. A. Kim, S. Saha, Y. W. Zhu and Y. H. Cho, "Optimal Structure Design for Minimizing Detent Force of PMLSM for a Ropeless Elevator", IEEE Trans. Magn., vol.50, no.1, pp.1,4, Jan. 2014. 
[21] Z. Q. Zhu and D. Howe. "Halbach permanent magnet machines and applications: a review", IEE Proc. Electric Power Appli., vol. 148, no. 4, Jul. 2001.

[22] S. De, M. Rajne, S. Poosapati, C. Patel and K. Gopakumar, "Lowinductance axial flux BLDC motor drive for more electric aircraft", IET Power Electron., vol.5, no.1, pp.124-133, Jan. 2012. 